\title{
Improving arable land heterogeneity information in available land cover products for land surface modelling using MERIS NDVI data
}

\author{
F. Zabel, T. B. Hank, and W. Mauser \\ Department of Geography, Ludwig-Maximilians-Universität, Munich, Germany
}

Received: 22 June 2010 - Published in Hydrol. Earth Syst. Sci. Discuss.: 5 July 2010

Revised: 15 October 2010 - Accepted: 18 October 2010 - Published: 26 October 2010

\begin{abstract}
Regionalization of physical land surface models requires the supply of detailed land cover information. $\mathrm{Nu}$ merous global and regional land cover maps already exist but generally, they do not resolve arable land into different crop types. However, arable land comprises a huge variety of different crops with characteristic phenological behaviour, demonstrated in this paper with Leaf Area Index (LAI) measurements exemplarily for maize and winter wheat. This affects the mass and energy fluxes on the land surface and thus its hydrology. The objective of this study is the generation of a land cover map for central Europe based on CORINE Land Cover (CLC) 2000, merged with CORINE Switzerland, but distinguishing different crop types. Accordingly, an approach was developed, subdividing the land cover class arable land into the regionally most relevant subclasses for central Europe using multiseasonal MERIS Normalized Difference Vegetation Index (NDVI) data. The satellite data were used for the separation of spring and summer crops due to their different phenological behaviour. Subsequently, the generated phenological classes were subdivided following statistical data from EUROSTAT. This database was analysed concerning the acreage of different crop types. The impact of the improved land use/cover map on evapotranspiration was modelled exemplarily for the Upper Danube catchment with the hydrological model PROMET. Simulations based on the newly developed land cover approach showed a more detailed evapotranspiration pattern compared to model results using the traditional CLC map, which is ignorant of most arable subdivisions. Due to the improved temporal behaviour and spatial allocation of evapotranspiration processes in the new land cover approach, the simulated water balance more closely matches the measured gauge.
\end{abstract}

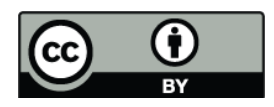

Correspondence to: F. Zabel (f.zabel@iggf.geo.uni-muenchen.de)

\section{Introduction}

The land surface and its properties are highly influenced by human activities such as agriculture or surface sealing. Land use/cover information is a key component of climate and hydrological models since the land cover primarily controls the energy fluxes on the land surface (Monteith and Unsworth, 1990; Lu and Shuttleworth, 2002; Masson et al., 2002). In a land use/cover map, each pixel of the land surface is associated to a label that characterizes the land use/cover following a predefined nomenclature. The accuracy of land use/cover products has a strong effect on the model results (Ge et al., 2007). The regional hydrological relevance of the mapped agricultural land cover heterogeneity is the focus of this paper.

\subsection{Existing land use/cover maps}

Thanks to the development of new remote sensing sensors with improved spatial and spectral resolution, various global, regional and local classifications with a spatial resolution of $1 \mathrm{~km}$ or even higher exist (Defries and Belward, 2000; Cihlar, 2000; Herold et al., 2007). ECOCLIMAP, for example, is a well-known global land cover product with a spatial resolution of $1 \mathrm{~km}$ (Masson et al., 2002). The Global Land Cover (GLC) 2000 classification compiled by the Joint Research Centre (JRC) and the European Space Agency (ESA) using SPOT-4 remote sensing data also features a spatial resolution of $1 \mathrm{~km}$ (Bartholomé and Belward, 2005). As a successor of GLC 2000, GLOBCOVER uses ENVISAT MERIS fine resolution data $(300 \mathrm{~m})$ for mapping the global land cover (Arino et al., 2007; Defourny et al., 2006). The MERIS images used for the GLOBCOVER product were acquired between January 2005 and June 2006 within the frame of the ESA GLOBCOVER project (Bicheron et al., 2008). The data are provided by POSTEL (Pôle d'Observation des Surfaces

Published by Copernicus Publications on behalf of the European Geosciences Union. 
continentales par TELédétection). These land cover products use different thematic legends but are fully compatible with the LCCS (Land Cover Classification System) used by the Food and Agriculture Organisation (FAO) and the United Nations Environment Programme (UNEP), which comprises 22 different types of land cover (Di Gregorio et al., 2000). As these maps provide global land cover information, they may not necessarily be suitable for regional or local studies. The CORINE Land Cover (CLC) classification is the most detailed regional land cover product available for $\mathrm{Eu}-$ rope. It distinguishes 44 classes of land cover with a spatial resolution of $100 \mathrm{~m}$ (Heymann et al., 1994; EEA, 2006; Bossard et al., 2000). The data are available for download at the EEA (European Environmental Agency). Many studies comparing the available land cover products e.g. CLC 2000 and GLC 2000 (Neumann et al., 2007; Herold et al., 2007) provide information on applicability and accuracy of the different maps.

\subsection{Heterogeneity of arable land}

Energy and matter fluxes are influenced directly by the land surface. Vegetation is a key element for SVAT (Soil-Vegetation-Atmosphere-Transfer) models, regarding its function as an interface between the land surface and the atmosphere (e.g. as a regulator of transpiration) (Monteith and Unsworth, 1990). The land surface has a strong feedback effect on the atmosphere and hence on the climate (Bounoua et al., 2000). Unfortunately most global and regional land cover datasets derived from satellites group croplands into just a few categories, thereby excluding information that is critical for answering key questions of current research (Monfreda et al., 2008; Herold et al., 2007). According to CLC, arable land accounts for $46 \%$ of the study area and thereby represents the class with the largest proportion of all land cover classes in central Europe. However, croplands include a variety of species with different phenology and physiology (Lokupitiya et al., 2009).

Exemplarily shown in Fig. 1 for maize and winter wheat based on the temporal development of Leaf Area Index (LAI), the growth cycles of specific crops may differ largely. While the main growth period of winter wheat occurs between May and June, the measurements show that maize grows fastest between July and August.

The ground based LAI measurements shown in Fig. 1 were collected during a field campaign conducted in southern Germany (approx. $25 \mathrm{~km}$ south-west of the city of Munich), monitoring maize and winter wheat stands during the growing season in 2004. The data points represent values of total LAI, measured by means of the Plant Canopy Analyzer LAI2000 instrument (LICOR Inc., Lincoln, NE, USA). Each point corresponds to the average of five individual sample points within a winter wheat and a maize stand respectively. Vertical error bars indicate the observed minimum and maximum within each of the test fields. Although the inves-

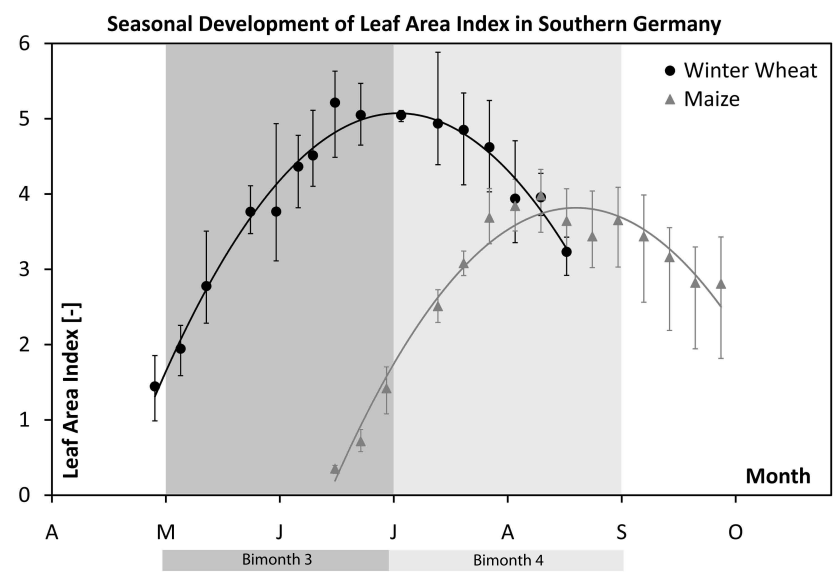

Fig. 1. Seasonal development of LAI for maize and winter wheat for a test side in southern Germany (April to October 2004). Vertical error bars represent the minimum and maximum observations.

tigated stands were comparably homogenous and strongly developed, which may cause the absolute values to appear slightly elevated compared to less well developed fields, the general seasonal growth pattern can be considered representative for these crops in southern Germany. The distinct difference of the temporal dynamics of leaf area accumulation and decrease of wheat and maize accounts well for the characteristic seasonal growth patterns of both crops. While the wheat site was ripening during July and already harvested at the beginning of August, the maize site did not reach its maximum development before the beginning of September. Since the displayed values were derived from non-destructive measurements, only the total LAI of the crops can be considered. If the effect of chlorophyll decomposition during the ripening phase is additionally taken into account, the seasonal disparities between both crops would become even more apparent. Nonetheless, the readings displayed in Fig. 1 clearly indicate that there is a temporal gap in the seasonal behaviour of maize and winter wheat of about 2 months. Bsaibes et al. (2009) showed similar results for temporal dynamics of LAI in southern France with a temporal shift forward in time of approximately 2 weeks. Those findings support the assumption of this typical seasonal behaviour of LAI development for the entire European area of interest.

The different phenology not only has an impact on the primary productivity during the growing season but also on the energy and matter fluxes such as evapotranspiration, sensible heat flux or long- and shortwave outgoing radiation as well as on $\mathrm{CO}_{2}$ fluxes or soil moisture (Lokupitiya et al., 2009). This must be taken into account when modelling the processes on the land surface. A diverse vegetation phenology within the arable land makes it necessary to split this class into subdivisions of different crop types. Approaches for unmixing cropland out of multitemporal remote sensing data have been carried out successfully using NOAA/AVHRR time series 
Table 1. PROMET land use/cover classes.

\begin{tabular}{llllll}
\hline ID & PROMET class & ID & PROMET class & ID & PROMET class \\
\hline 1 & Extensive Grassland & 10 & Potato & 19 & Residential Built-Up \\
2 & Intensive Grassland & 11 & Rye & 20 & Deciduous Forest \\
3 & Silage & 12 & Setaside & 21 & Coniferous Forest \\
4 & Forage & 13 & Sugar Beet & 22 & Rock \\
5 & Hop & 14 & Summer Barley & 23 & Wetland \\
6 & Legumes & 15 & Summer Wheat & 24 & Alpine Vegetation \\
7 & Maize & 16 & Winter Barley & 25 & Natural Grassland \\
8 & Oat & 17 & Winter Wheat & 26 & Glacier \\
9 & Oleaginous & 18 & Industrial Built-Up & 27 & Water \\
\hline
\end{tabular}

(Probeck et al., 2003). Studies for higher resolution information nevertheless show that amounts of manual interpretation and cloud-free high spatial resolution imagery are required for operational implementation over large areas and in multiple years (Lobell and Asner, 2004). However, the approach described in this paper uses existing land cover products improving them with the help of remote sensing products combined with statistical data.

\section{Method}

\subsection{Area of interest}

The study area is situated in Central Europe and extends $1170 \mathrm{~km}$ north-south by $1170 \mathrm{~km}$ east-west including $18 \mathrm{Eu}-$ ropean countries, 6 of them not being members of the European Union (Fig. 2). Plains like the Po Valley, uplands like in central Germany and the Alps that mark a climatic boundary between the temperate latitudes and the Mediterranean climate dominate the landscape. Altitudes are ranging from the Mont Blanc in the French Alps $(4.810 \mathrm{~m})$ to the Atlantic Ocean in the north-west and the Mediterranean Sea in the south. In between, a wide range of different land covers occurs, which are strongly influenced by man. The area is characterized by intense agriculture especially within the fertile lowlands like the Upper Rhine or the Po Valley.

\subsection{Hydrological model}

The physically based hydrological model PROMET (Processes of Radiation, Mass and Energy Transfer) used in this study to investigate the regional impact of agricultural land information was developed and validated for the Upper Danube catchment (Mauser and Bach, 2009; Mauser and Schädlich, 1998). The model can be operated on variable scales, but was applied with a spatial resolution of $1 \mathrm{~km}$ in this study. Hence, a land use/cover scheme that serves as an input for PROMET at least needs the same spatial resolution. As PROMET uses its own land use/cover parameterization, the nomenclature of the land use/cover classification and the

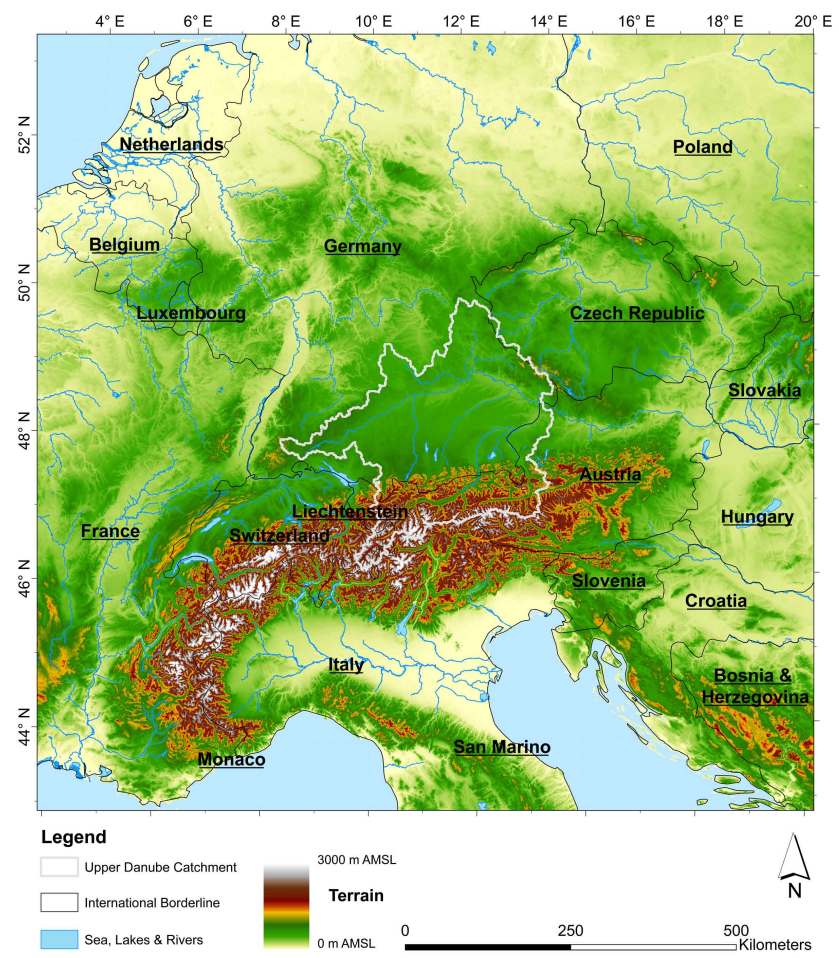

Fig. 2. Topography (based on SRTM data) of the area of interest, showing the European countries as well as the boundaries of the Upper Danube catchment.

model parameterization have to match. The parameterization scheme in PROMET discerns 27 classes (Table 1) within the first 17 are different types of land occupied by agriculture. The parameterization was created for the watershed of the Upper Danube. The included classes therefore are restricted to the regional particularities of the land cover for this region (Ludwig et al., 2003). The parameterization of individual land surface classes is due to physical plant properties gathered from measurements. Therefore, the plant parameterization in PROMET is restricted to specific plant types. Accordingly, mixed vegetation classes like "mixed forest" 


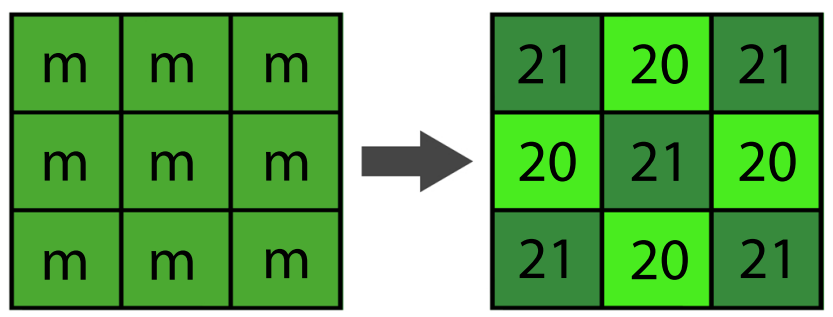

Fig. 3. Reclassification of forested areas labelled as "mixed forest" (m) to an evenly distribution of deciduous (20) and coniferous (21) forest. The Pixels are alternately classified to coniferous and deciduous.

are avoided in PROMET. The motivation for developing a regional land cover map for the larger extent of the area of interest is the need for a detailed description of the European land cover that allows for two-way coupling of PROMET with the regional climate model MM5 (Zabel et al., 2010).

\subsection{Land use/cover classification}

\subsubsection{Fusion of CLC 2000 and CLC Switzerland and adaptation to PROMET}

As this study is concentrating on central Europe, the CLC 2000 (version 9/2007) classification was well suited for further processing in order to allow for a later use with the PROMET model. CLC 2009 is in progress but not available for all European countries, yet. Since the 44 CLC 2000 classes do not match the parameterization of vegetation and land cover in PROMET, a transformation from the CLC 2000 classification system to the thematic legend of PROMET was necessary. This was done following the conversion scheme shown in Table 2.

Although the CLC 2000 classes "rice fields", "vineyards", "fruit trees \& berry plantations", and "olive groves" are not implemented in the parameterization of PROMET yet (as they are irrelevant in the Upper Danube catchment), they were not reclassified in order to be able to introduce the crop specific parameterization to PROMET at a later point in time. The compiled classes "arable land" and "pasture", which are both not parameterized in PROMET, now state the basis for a further processing described in Sects. 2.3.2 and 2.3.3. Since "mixed forest" does not exist within the land cover nomenclature of PROMET, it was evenly distributed into the coniferous and deciduous forest category using a uniform pattern (Fig. 3).

Since Switzerland is missing within the CLC 2000, the map was completed with the CLC 1990 Switzerland classification having a spatial resolution of $250 \mathrm{~m}$ and again using a different nomenclature of land use/cover classification. Land use/cover change from 1990 to 2000 in Switzerland is supposed to be negligible. The transformation of the Swiss land cover classification to the PROMET classes is shown in Table 3 .
As Table 3 demonstrates, CLC 1990 Switzerland has a lack of glaciers and no differentiation between coniferous and deciduous forest. The glaciers for Switzerland were added using the GLOBCOVER glacier classification (Bicheron et al., 2008) as a glacier mask for the new classification approach. Furthermore, the Swiss forest was divided into coniferous and deciduous forest by using statistical data of the Swiss Federal Statistical Office for each canton (Table 4).

First, all Swiss forested area located at elevations above $1200 \mathrm{~m}$ was generally reclassified to coniferous forest according to the following rule.

If the land cover was "forest" and the altitude was higher than $1200 \mathrm{~m}$, then the land cover was reclassified to "coniferous forest".

This corresponds to the climatic limit of deciduous forest in Switzerland. The underlying digital elevation model (DEM) used for this decision consisted of $90 \mathrm{~m}$ Shuttle Radar Topography Mission (SRTM) data. After the entire forest above $1200 \mathrm{~m}$ was identified as coniferous forest, the rest of the forested area was reclassified following the statistical allocation for each canton (Swiss Federal Statistical Office, 2004) (Table 4), subtracting the coniferous forested area above $1200 \mathrm{~m}$ that has already been classified. The sections "mixed coniferous forest" and "mixed deciduous forest" of the statistics each have a fraction of $50-90 \%$ of coniferous or deciduous forest respectively but were regarded as unmitigated $(100 \%)$ coniferous or deciduous forest.

After the modified and reclassified CLC 2000 and CLC 1990 Switzerland were merged to one map, more adaptations were necessary for a subsequent division of the class "natural grassland". In order to meet the regional characteristics of the alpine vegetation, the class "natural grassland" was further reclassified to "rock" or "alpine vegetation" based on three assumptions:

- if the land cover was "natural grassland" and the altitude was higher than $2400 \mathrm{~m}$, then the land cover was reclassified to "rock".

- if the land cover was "natural grassland" and the altitude was between $1400 \mathrm{~m}$ and $2400 \mathrm{~m}$, then the land cover was reclassified to "alpine vegetation".

- if the land cover was "natural grassland" and the slope was higher than $30 \%$, then the land cover was reclassified to "rock".

\subsubsection{Subdivision of arable land via MERIS NDVI data}

Thus, a land cover map for central Europe was created by merging the CLC 2000 and CLC Switzerland into one consistent land use/cover map and translating them into the PROMET nomenclature. Further, it was necessary to divide the class "arable land" into subclasses in order to cover the natural heterogeneity of different crop types in central 
Table 2. Transformation of CORINE Land Cover 2000 into the PROMET classes.

\begin{tabular}{|c|c|c|c|c|}
\hline ID & LABEL3 & & ID & LABEL \\
\hline 1.1.1. & Continuous urban fabric & $\rightarrow$ & 19 & Residential Built-Up \\
\hline 1.1.2. & Discontinuous urban fabric & $\rightarrow$ & 19 & Residential Built-Up \\
\hline 1.2.1. & Industrial or commercial units & $\rightarrow$ & 18 & Industrial Built-Up \\
\hline 1.2.2. & Road and rail networks and associated land & $\rightarrow$ & 18 & Industrial Built-Up \\
\hline 1.2.3. & Port areas & $\rightarrow$ & 18 & Industrial Built-Up \\
\hline 1.2.4. & Airports & $\rightarrow$ & 18 & Industrial Built-Up \\
\hline 1.3.1. & Mineral extraction sites & $\rightarrow$ & 18 & Industrial Built-Up \\
\hline 1.3.2. & Dump sites & $\rightarrow$ & 18 & Industrial Built-Up \\
\hline 1.3.3. & Construction sites & $\rightarrow$ & 18 & Industrial Built-Up \\
\hline 1.4.1. & Green urban areas & $\rightarrow$ & 19 & Natural Grassland \\
\hline 1.4.2. & Sport and leisure facilities & $\rightarrow$ & 19 & Natural Grassland \\
\hline 2.1.1. & Non-irrigated arable land & $\rightarrow$ & & Arable Land \\
\hline 2.1.2. & Permanently irrigated land & $\rightarrow$ & & Arable Land \\
\hline 2.1.3. & Rice fields & $\rightarrow$ & & Rice Fields \\
\hline 2.2.1. & Vineyards & $\rightarrow$ & & Vineyards \\
\hline 2.2.2. & Fruit trees \& berry plantations & $\rightarrow$ & & Fruits \& Berries \\
\hline 2.2.3. & Olive groves & $\rightarrow$ & & Olive Groves \\
\hline 2.3.1. & Pasture & $\rightarrow$ & & Pasture \\
\hline 2.4.1. & Annual crops associated with permanent crops & $\rightarrow$ & & Arable Land \\
\hline 2.4.2. & Complex cultivation patterns & $\rightarrow$ & & Arable Land \\
\hline 2.4.3. & $\begin{array}{l}\text { Land principally occupied by agriculture, with } \\
\text { significant areas of natural vegetation }\end{array}$ & $\rightarrow$ & & Arable Land \\
\hline 2.4.4. & Agro-forestry areas & $\rightarrow$ & 21 & Coniferous Forest \\
\hline 3.1.1. & Broad-leaved forest & $\rightarrow$ & 20 & Deciduous Forest \\
\hline 3.1.2. & Coniferous forest & $\rightarrow$ & 21 & Coniferous Forest \\
\hline 3.1.3. & Mixed forest & $\rightarrow$ & $20 / 21$ & $\begin{array}{l}50 \% \text { Deciduous Forest, } \\
50 \% \text { Coniferous Forest }\end{array}$ \\
\hline 3.2.1. & Natural grasslands & $\rightarrow$ & 25 & Natural Grassland \\
\hline 3.2.2. & Moors and heathland & $\rightarrow$ & 23 & Wetland \\
\hline 3.2.3. & Sclerophyllous vegetation & $\rightarrow$ & 25 & Natural Grassland \\
\hline 3.2.4. & Transitional woodland-shrub & $\rightarrow$ & 20 & Deciduous Forest \\
\hline 3.3.1. & Beaches, dunes, sands & $\rightarrow$ & 22 & Rock \\
\hline 3.3.2. & Bare rocks & $\rightarrow$ & 22 & Rock \\
\hline 3.3.3. & Sparsely vegetated areas & $\rightarrow$ & 25 & Natural Grassland \\
\hline 3.3.4. & Burnt areas & $\rightarrow$ & 25 & Natural Grassland \\
\hline 3.3.5. & Glaciers and perpetual snow & $\rightarrow$ & 26 & Glacier \\
\hline 4.1.1. & Inland marshes & $\rightarrow$ & 23 & Wetland \\
\hline 4.1.2. & Peat bogs & $\rightarrow$ & 23 & Wetland \\
\hline 4.2.1. & Salt marshes & $\rightarrow$ & 23 & Wetland \\
\hline 4.2.2. & Salines & $\rightarrow$ & 23 & Wetland \\
\hline 4.2.3. & Intertidal flats & $\rightarrow$ & 23 & Wetland \\
\hline 5.1.1. & Water courses & $\rightarrow$ & 27 & Water \\
\hline 5.1.2. & Water bodies & $\rightarrow$ & 27 & Water \\
\hline 5.2.1. & Coastal lagoons & $\rightarrow$ & 27 & Water \\
\hline 5.2.2. & Estuaries & $\rightarrow$ & 27 & Water \\
\hline 5.2.3. & Sea and ocean & $\rightarrow$ & 27 & Water \\
\hline
\end{tabular}

Europe. Figure 1 demonstrates the different phenological development of maize and winter wheat, using LAI as example. The context of these measurements (Sect. 1.2) can be transferred to the Normalized Differenced Vegetation Index (NDVI), because of a strong correlation between LAI and NDVI (Baret and Guyot, 1991; Bach 1995). In order to classify the distinct phenological behaviours of different crops according to their photosynthetic activity (maximum LAI/NDVI in spring or summer), a multiseasonal NDVI dataset gathered from POSTEL (Pôle d'Observation 
Table 3. Transformation of the CORINE Land Cover 1990 Switzerland into the PROMET classes.

\begin{tabular}{lllll}
\hline ID & LABEL1 & & ID & PROMET-LABEL \\
\hline 11 & Urban fabric & $\rightarrow$ & 19 & Residential Built-Up \\
12 & Industrial, commercial and transport units & $\rightarrow$ & 18 & Industrial Built-Up \\
13 & Mine, dump and construction sites & $\rightarrow$ & 18 & Industrial Built-Up \\
14 & Artificial non-agricultural vegetated areas & $\rightarrow$ & 19 & Residential Built-Up \\
21 & Arable land & $\rightarrow$ & & Arable Land \\
22 & Permanent crops & $\rightarrow$ & & Arable Land \\
23 & Pasture & $\rightarrow$ & & Pasture \\
24 & Heterogeneous agricultural areas & $\rightarrow$ & & Arable Land \\
31 & Forests & $\rightarrow$ & $20 / 21$ & Deciduous/Coniferous Forest \\
32 & Shrub and/or herbaceous vegetation associations & $\rightarrow$ & 25 & Natural Grassland \\
33 & Open spaces with little or no vegetation & $\rightarrow$ & Natural Grassland \\
41 & Inland wetlands & $\rightarrow$ & 23 & Wetland \\
51 & Inland waters & $\rightarrow$ & Water \\
\hline
\end{tabular}

Table 4. Statistical distribution of coniferous and deciduous forest $\left[\mathrm{km}^{2}\right]$ for each Swiss canton (Swiss Federal Statistical Office, 2004).

\begin{tabular}{lrrrrrr}
\hline Canton & $\begin{array}{r}\text { Coniferous } \\
\text { Forest }\end{array}$ & $\begin{array}{r}\text { Mixed } \\
\text { Coniferous } \\
\text { Forest }\end{array}$ & $\begin{array}{r}\text { Mixed } \\
\text { Deciduous } \\
\text { Forest }\end{array}$ & $\begin{array}{r}\text { Deciduous } \\
\text { Forest }\end{array}$ & $\begin{array}{r}\text { Total } \\
\text { Forest }\end{array}$ & $\begin{array}{r}\text { Not } \\
\text { classified }\end{array}$ \\
\hline Région Lémanique & 955 & 414 & 278 & 226 & 1873 & 37 \\
Espace Mittelland & 1105 & 856 & 693 & 417 & 3070 & 80 \\
Nordwestschweiz & 108 & 167 & 229 & 149 & 654 & \\
Zürich & 165 & 143 & 136 & 46 & 489 & \\
Ostschweiz & 1708 & 494 & 361 & 231 & 2794 & 65 \\
Zentralschweiz & 564 & 327 & 208 & 95 & 1195 & 19 \\
Tessin & 351 & 189 & 139 & 601 & 1279 & 26 \\
\hline
\end{tabular}

des Surfaces continentales par TELédétection) was taken into account (Bicheron et al., 2008). With a spatial resolution of $300 \mathrm{~m}$, it provides information about the photosynthetic activity of vegetation in a two monthly temporal resolution. The dataset can be accessed online free of charge from bimonth 6, 2004 to bimonth 3, 2006 via the POSTEL portal. This approach uses two NDVI scenes of bimonth 3 (May, June) and bimonth 4 (July, August) from the year 2005, since the different photosynthetic activities at these points in time can be used to make assumptions about the type of crop that is growing (Fig. 1). Preparing the data for a change detection approach, the bimonth 4 imagery was subtracted from bimonth 3 (Fig. 4). The blue coloured areas in Fig. 4 indicate a phenological behaviour of crops with a photosynthetic maximum in spring while red coloured areas indicate a temporal shift of plant activity to summer. Obviously, within the area of interest, significant distinctions in temporal change of NDVI can be made. It is striking that some regions like the northern part of the Po Valley, are clearly distinguished from others.
Using a decision tree as shown in Fig. 5, the change of NDVI, masked with the area of arable land was classified into three different phenological classes.

The NDVI may return values between 0 and 1 for the dry land surface. Detected changes falling below 0.1 were treated as being within a range of uncertainty and thus were classified as "equally-active". Changes exceeding 0.1 were classified as "spring-crops" or "summer-crops" respectively.

As a result it is possible to differentiate between the phenological classes "spring-crops", "summer-crops" and vegetation that does not show a change in activity within this time period, called "equally active" (Fig. 6). The denotation "summer-crops" groups all kinds of crop plants like maize, potato, sugar beet or legumes that show a phenological behaviour with the highest rate of growth in summer and that significantly exist within the area of interest, while "springcrops" are e.g. winter wheat, winter barley, rape, oat or rye with highest rates of growth in spring. Regions dominated by "summer-crops" can be recognized e.g. in the Rhine Valley (Fig. 6). The Po Valley shows a separation into "summercrops" north and "spring-crops" south of the Po. Along the 


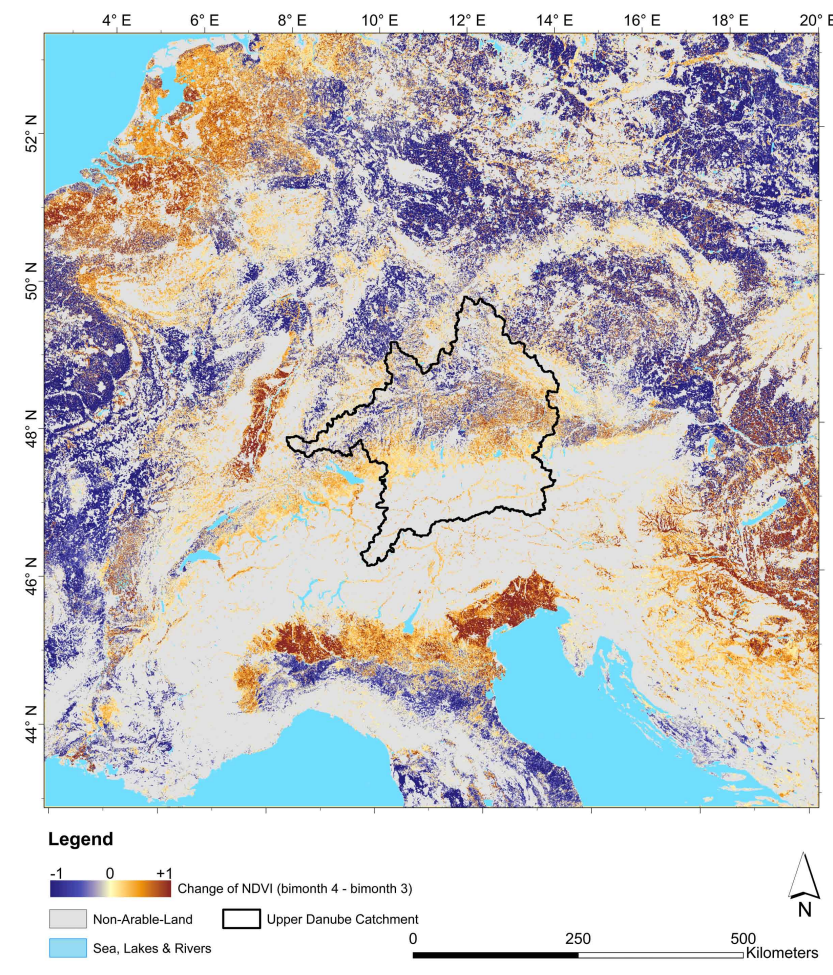

Fig. 4. Temporal change of MERIS NDVI, masked for arable land as a subtraction of Bimonth 4 with Bimonth 3 .

Po River, "equally-active" land was classified. While central Germany, Poland as well as the Czech Republic are mostly covered with "spring-crops", Hungary, Croatia in the east but also the Netherlands and Belgium in the north-west are mainly covered by "summer-crops". The resulting map subsequently is used for a further statistical subdivision of these phenological-classes to specific crop types.

\subsubsection{Statistical subdivision of phenological classes}

This was done with the help of statistical information from the Statistical Office of the European Communities (EUROSTAT) for each so-called NUTS region (Nomenclature des unités territoriales statistiques) in the area of interest. The NUTS regions represent administrative regions within the countries of the European Union. The EUROSTAT dataset used for this study includes information on the 2006 acreage of different crop types for each NUTS region. The gathered classes "spring-crops", "summer-crops", "equallyactive" and "pasture" (Fig. 6) are subdivided with the help of the statistical dataset. The classes "rice", "vine" and "olives" are already spatially located within the CLC 2000 dataset and therefore do not need to be taken into account for the statistical reclassification. A check-up showed that the sum of area of these classes agrees fairly well with the EUROSTAT statistics for each NUTS region. All vegetables of the statistics were merged with the class "fruits \& berries". Therefore, the class label changed to "vegetables, fruits \& berries".
Subtraction: Bimonth 4 - Bimonth 3

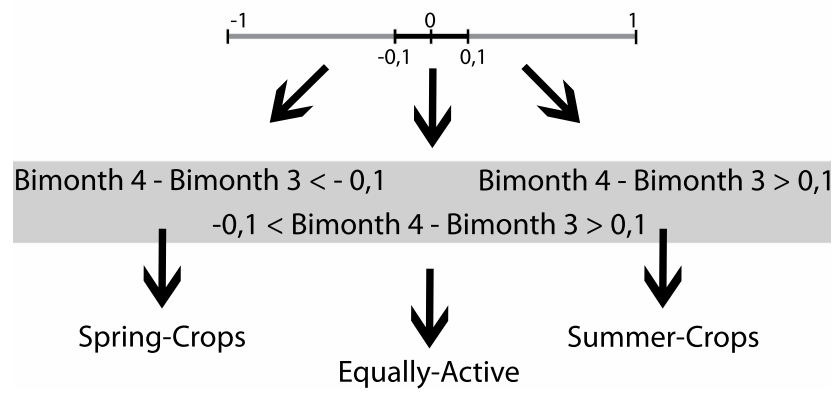

Fig. 5. Decision tree for the differentiation of three phenological categories (spring, summer, equal) using the change signal of two MERIS NDVI images for Bimonth 3 and Bimonth 42005.

Among the other classes, the absolute amount of area associated to each crop type was converted into the percentage of arable land for each NUTS region. Finally, the regional distribution was based on a decision scheme as shown in Table 5. According to the priorities listed in Table 5, the first class to be distributed was winter wheat since it is the most widely spread crop type in central Europe. As winter wheat is a spring active crop type, it was evenly distributed into the class "spring-crops" for each NUTS region. If the spring crop area derived from MERIS was too small to contain all the winter wheat area that should be distributed according to the statistics, the remaining winter wheat areas were further distributed evenly among the class "equally-active", according to the "Fill-up-Order" in Table 5. Following the priority of Table 5, the next crop type to be distributed was maize as it is the second most frequent land use of arable land within the area of interest.

\section{Results}

\subsection{Resulting land use/cover map}

As a result, the percentage of each individual subclass of arable land matches the statistical percentage derived from the EUROSTAT statistical data for each NUTS region. However, due to the purely statistical distribution, there is no guarantee for the correct spatial positioning of the pixels. Hence, an accuracy matrix as it is often shown to demonstrate the significance of a land use/cover classification cannot be applied at this point. Nonetheless, the likelihood for a correct placement of a pixel was increased by using the multitemporal NDVI dataset.

Figure 7 shows the resulting land cover map including 18 subclasses of land occupied by agriculture at a spatial resolution of $1 \mathrm{~km}$. In order to allow for subscale modelling, the same approach was applied for the generation of a $100 \mathrm{~m}$ land cover map using CLC $(100 \mathrm{~m})$ as base data. In this case, the MERIS NDVI images were resampled from $300 \mathrm{~m}$ to the final resolution of $100 \mathrm{~m}$. 
Table 5. Priority list and "Fill-up-Order" for the statistical reclassification of "spring-crops", "summer-crops" and "equally-active" crops into 15 different types of arable land.

\begin{tabular}{|c|c|c|}
\hline Priority & Class & Fill-up-Order \\
\hline & Group: Summer-Crops & \\
\hline 2. & Maize & 1. Summer-Crops \\
\hline 3. & Silage & 2. Equally-Active \\
\hline 10. & Potato & 3. Spring-Crops \\
\hline 11. & Sugar Beet & 4. Pasture \\
\hline \multirow[t]{2}{*}{15.} & Legumes & 5. Vegetables, Fruits \& Berries \\
\hline & Group: Spring-Crops & \\
\hline 1. & Winter Wheat & 1. Spring-Crops \\
\hline 4. & Winter Barley & 2. Equally-Active \\
\hline 9. & Oleaginous & 3. Summer-Crops \\
\hline 12. & Oat & 4. Pasture \\
\hline \multirow[t]{2}{*}{13.} & Rye & 5. Vegetables, Fruits \& Berries \\
\hline & Group: Grassland & \\
\hline 5. & Extensive Grassland & 1. Pasture \\
\hline 6. & Intensive Grassland & 2. Equally-Active \\
\hline \multirow[t]{4}{*}{7.} & Forage & 3. Spring-Crops \\
\hline & & 4. Summer-Crops \\
\hline & & 5. Vegetables, Fruits \& Berries \\
\hline & Group: Set-aside & \\
\hline \multirow[t]{6}{*}{8.} & Set-aside & 1. Equally-Active \\
\hline & & 2. Pasture \\
\hline & & 3. Summer-Crops \\
\hline & & 4. Spring-Crops \\
\hline & & 5. Vegetables, Fruits \& Berries \\
\hline & Group: Vegetable, Fruits \& Berries & \\
\hline \multirow[t]{5}{*}{14} & Vegetables, Fruits \& Berries & 1. Vegetables, Fruits \& Berries \\
\hline & & 2. Spring-Crops \\
\hline & & 3. Equally-Active \\
\hline & & 4. Summer-Crops \\
\hline & & 5. Pasture \\
\hline
\end{tabular}

The patterns of Fig. 6 still can be recognized in Fig. 7 e.g. in the region of the Rhine Valley that is dominated by maize according to the statistical reclassification. This can be taken as an indication for the reliability of the NDVI approach, since the NUTS statistics match the NDVI in the Rhine Valley well (compare Figs. 6 and 7). In addition, the segregation within the Po-Valley is reproduced in Fig. 7 in comparison with Fig. 6. Partly, the agricultural areas are fragmented and heterogeneous, due to the applied even distribution method. Due to a lack of the statistical data for Croatia as well as for Bosnia and Herzegovina, all "summer-crops" in that area were reclassified to maize and all "spring-crops" to winter wheat, while the class "equally-active" was labelled as pasture.

\subsection{Impact on simulated evapotranspiration}

As the new land use/cover approach is accounting for the spatial heterogeneity of arable land and thus is respecting the different phenological behaviour of different crop types, modelled evapotranspiration is expected to be improved using the new land use/cover approach. Therefore, the model PROMET (Mauser and Bach, 2009) was applied to the simulation of the hydrology of the Upper Danube catchment exemplarily, using three different land use/cover schemes as input data.

The first two land cover schemes both consisted of the reclassified CLC 2000 and CLC Switzerland neglecting the subdivision of arable land. A plant parameterization of the class "arable land" is not possible. Only a mixed parameterization of a homogeneous class "arable land" could handle the diversity of crops within the class "arable land". Nonetheless, this cannot reasonably represent reality. Therefore, all arable land was consequently reclassified to maize (CLC maize) respectively winter wheat (CLC winter wheat) since PROMET is well parameterized for the simulation of these crop types. Maize and winter wheat were assumed to represent summer (maize) and spring crops (winter wheat) respectively as these classes state two possible extremes. The third land cover scheme finally consisted of the improved 


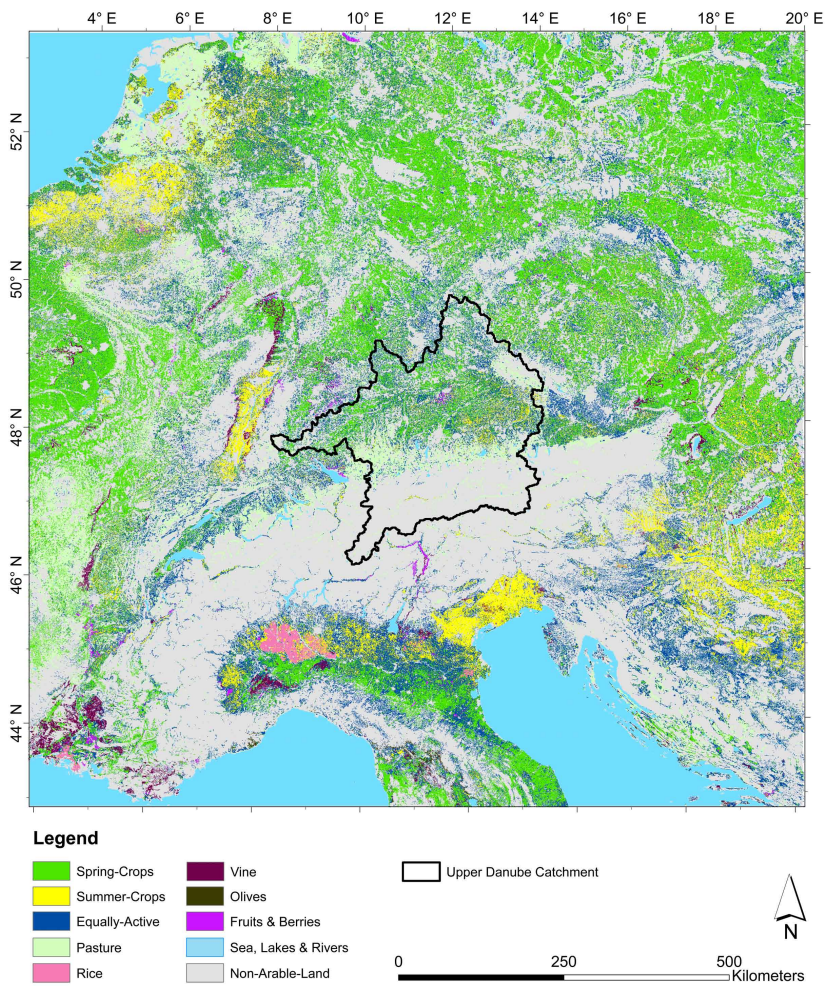

Fig. 6. Phenological subclasses of arable land from CLC after splitting with MERIS NDVI.

land cover approach mapped in Fig. 7 (New approach). Investigating the hydrological impact, the evapotranspiration was modelled with PROMET using a spatial resolution of $1 \mathrm{~km}$ and a temporal increment of $1 \mathrm{~h}$ for the time period from 1971-2000. The model was driven by spatially interpolated meteorological data from 277 weather stations (Mauser and Bach, 2009).

Comparing the modelled monthly mean evapotranspiration of "CLC winter wheat" and "CLC maize" (Fig. 8) for the month of May as well as for August, a distinct behaviour in evapotranspiration due to the different phenological development of spring- and summer crops is obvious. While the "CLC winter wheat" classification in May already shows high values of monthly evapotranspiration for the winter wheat areas of up to $70 \mathrm{~mm}$, the maize classification (CLC maize) does not contribute to evapotranspiration yet (Fig. 8). In August, however, the winter wheat already is harvested and therefore does not transpire anymore, while the maize transpires between $80 \mathrm{~mm}$ and $100 \mathrm{~mm}$ per month and therefore is heavily involved with the catchment evapotranspiration. This clearly demonstrates a huge impact of the land use on the simulated evapotranspiration. Regional differences of up to $80 \mathrm{~mm}$ per month depending on whether the land use is maize or winter wheat may occur. Only within the new land use approach, it is possible to trace spring and summer active crops in the modelled evapotranspiration. This gives a

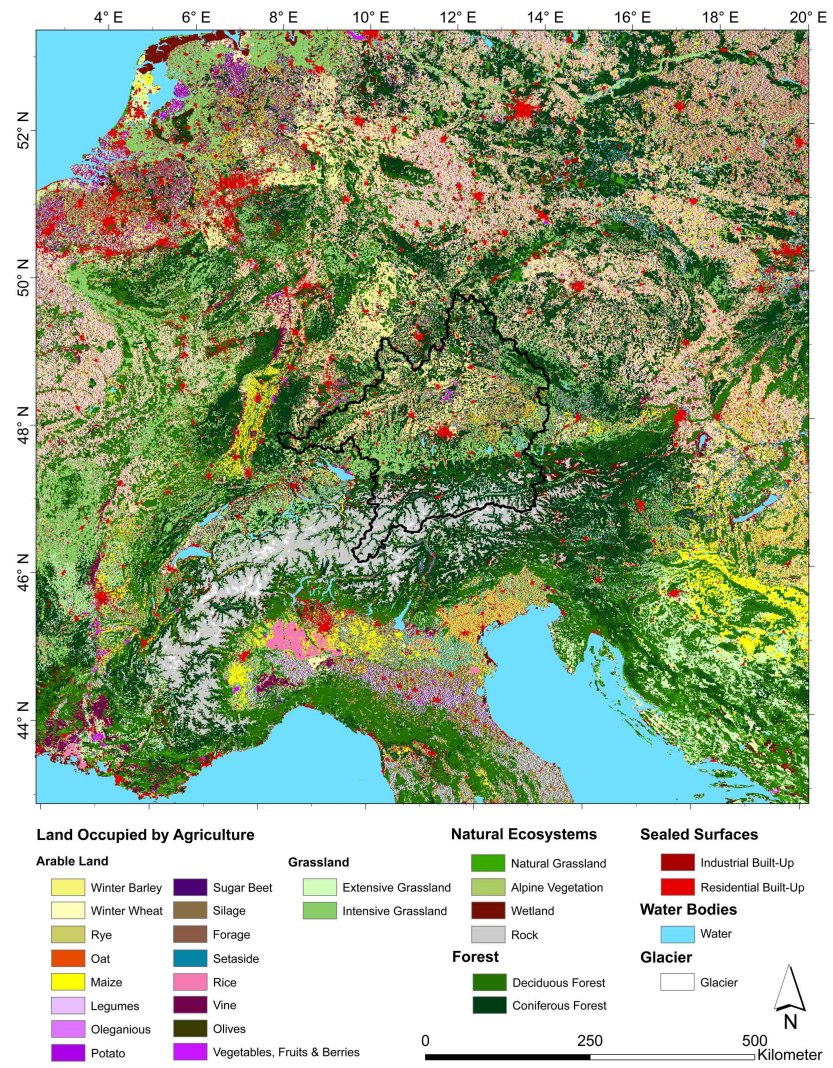

Fig. 7. Resulting land cover map based on CLC 2000 and CLC 1990 Switzerland and being transformed to the PROMET classification, after phenological subclasses of arable land gathered by MERIS NDVI were further statistically reclassified with the help of the EUROSTAT dataset.

more realistic picture of the spatial behaviour of evapotranspiration in May and August. Spatial patterns of simulated evapotranspiration for the new land use approach in Fig. 8 indicate the different phenological state of spring and summer crops in May and August respectively. While spring active crops are dominating the northern part of the catchment area, summer active crops are dominating the eastern part according to the land cover distribution assumed in Fig. 7. Even more, the influence of the new land use approach on the evapotranspiration is supposed to be stronger in regions where a clear majority of spring or summer crops is cultivated, such as the Upper Rhine Valley, which is clearly dominated by maize. Other studies also found significant differences in evapotranspiration and energy fluxes corresponding to different crop types using similar model approaches (Richter and Timmermans, 2009).

\subsection{Validation of the water balance}

Figure 8 clearly indicates a huge impact of the land use/cover on the simulated evapotranspiration. This affects the simulated water balance in the Upper Danube catchment. In 

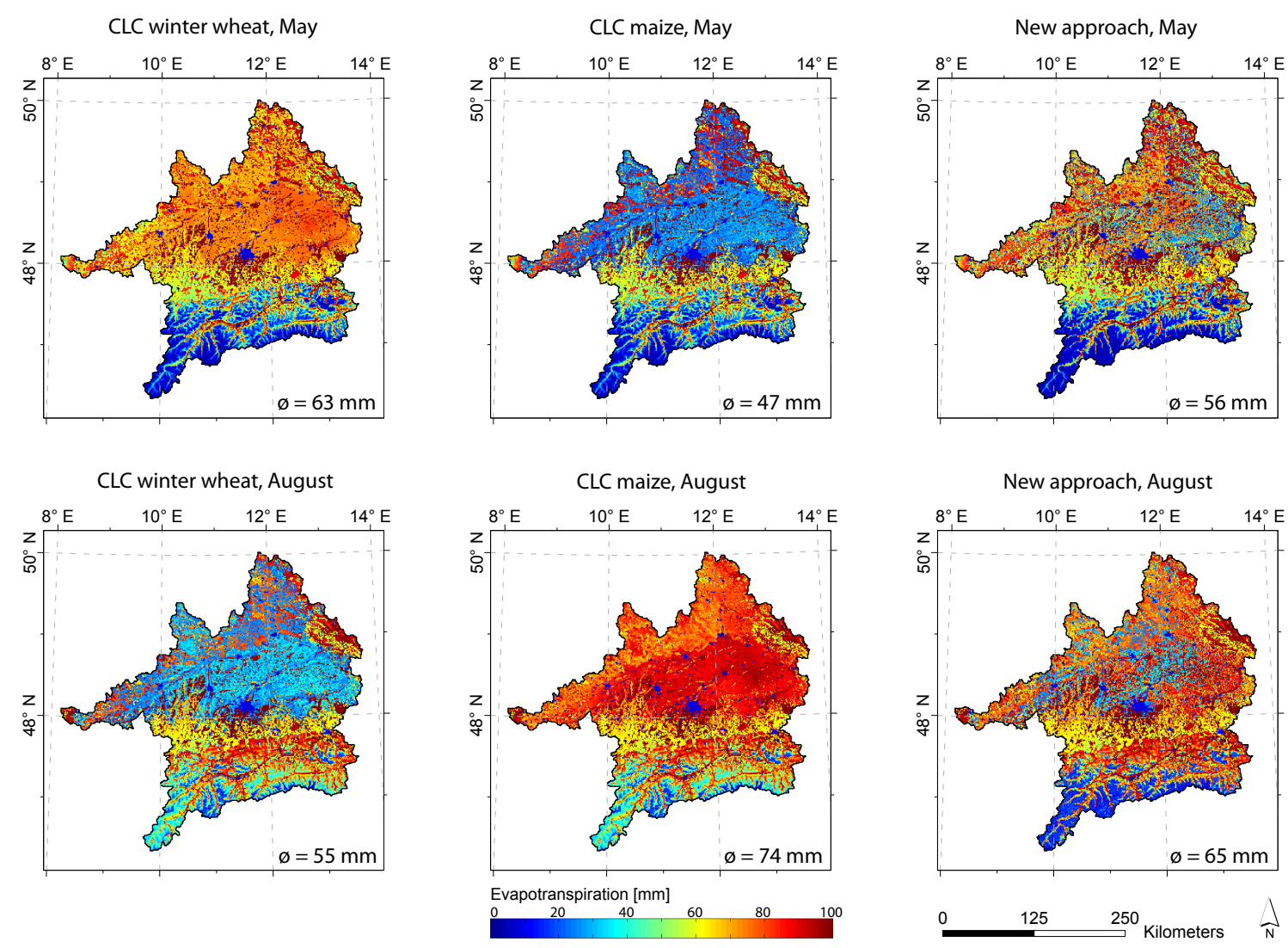

Fig. 8. Modelled mean monthly evapotranspiration (1971-2000) in May and August with three different land use/cover classification schemes implemented in PROMET (CLC winter wheat, CLC maize and the new land use/cover approach) for the Upper Danube catchment.

order to quantify the improvement of the new land use/cover approach, the water balance was calculated using the three land use/cover classifications "CLC winter wheat", "CLC maize" and the new land use approach. The resulting runoff was compared to the measured runoff volume at the outlet gauge in Achleiten. Since the Upper Danube catchment is evenly fractioned in spring and summer crops and therefore, the yearly evapotranspiration sums between the three land use classifications do not differ largely, the water balance for the whole year is supposed to be similar. Only during the growing season from May to September, the new land use approach has an impact on the amount of evapotranspiration and therefore on the water balance. Runoff formation in the Upper Danube catchment is predominantly influenced by snow cover dynamics. In order to clearly identify the improvement caused by the new land cover approach, the month of August was selected for further analysis since the influence of the snow cover was supposed to be comparably small.

The observed monthly mean precipitation in August (1971-2000) was $117 \mathrm{~mm}$. PROMET returned mean monthly evapotranspiration of $55 \mathrm{~mm}$ (CLC winter wheat), $74 \mathrm{~mm}$ (CLC maize) and $64 \mathrm{~mm}$ (New approach) respec- tively. According to the water balance, this leads to mean monthly runoff values of $62 \mathrm{~mm}$ (CLC winter wheat), $43 \mathrm{~mm}$ (CLC maize) and $53 \mathrm{~mm}$ (New approach) respectively. Compared to the measured runoff value gathered from the outlet gauge in Achleiten $(55 \mathrm{~mm})$, the new approach significantly improves the model results (see Table 6).

\section{Conclusions}

The changing characteristics of crop phenology in the course of the growing season due to differences in albedo, crop height, aerodynamic properties and leaf and stomata properties affect the mass - and energy fluxes on the land surface (Allen et al., 1998). As shown, LAI measurements clearly indicate a heterogeneous phenological behaviour of different crop types. In order to describe these effects in a physical model, a land use/cover scheme is necessary that supplies adequate heterogeneity with high spatial resolution, in combination with an accurate classification and parameterization of the plants properties. By grouping various crop types into only one mixed class of "arable land", most available land use/cover products cannot take the heterogeneity within the different crops into account. Therefore, we developed a land 
Table 6. Water balance of three PROMET simulations using the CLC winter wheat, the CLC maize and the new land use/cover approach in comparison to the measured gauge in Achleiten as mean values from 1971-2000 for the month of August.

\begin{tabular}{lrrrr}
\hline & Precipitation & Evapotranspiration & Runoff & $\begin{array}{r}\text { Measured Gauge } \\
\text { (Achleiten) }\end{array}$ \\
\hline CLC winter wheat & $117 \mathrm{~mm}$ & $55 \mathrm{~mm}$ & $62 \mathrm{~mm}$ & $55 \mathrm{~mm}$ \\
CLC maize & $117 \mathrm{~mm}$ & $74 \mathrm{~mm}$ & $43 \mathrm{~mm}$ & $55 \mathrm{~mm}$ \\
New approach & $117 \mathrm{~mm}$ & $64 \mathrm{~mm}$ & $53 \mathrm{~mm}$ & $55 \mathrm{~mm}$ \\
\hline
\end{tabular}

cover map that uses the high resolution of the CLC classification but comprises the heterogeneity of arable land. Thus, phenological classes due to multiseasonal MERIS NDVI imagery data were compiled in order to distinguish crop types following their different phenological behaviour. Subsequently, the generated phenological classes were subdivided following statistical data from EUROSTAT for each NUTS region. The land use/cover scheme strongly affects the simulated evapotranspiration of a hydrological model. Therefore, modelling the evapotranspiration for the Upper Danube catchment with the hydrological model PROMET, the new land use approach was compared to two possible extremes: In one case, the class arable land was interpreted as pure spring crop (winter wheat), whereas in a second case the complete arable land area was assumed to represent a summer crop (maize). With the new heterogeneous land cover approach, the regional characteristics of arable crops can be addressed with a higher level of detail. Due to those improvements, the simulated monthly evapotranspiration especially in May and August shows large differences in comparison with the simulations using the two possible homogeneous classifications, especially in regions dominated by spring or summer crops respectively. The different spatial and temporal behaviour of modelled evapotranspiration again affects the water balance for the Upper Danube catchment in case of the three land use classifications. The modelled runoff was compared to measured data from the outlet gauge in Achleiten for a 30-year period from 1971 to 2000. The new land use approach could improve the model results significantly. The importance of land use/cover information is increasing when investigating the interactions between the land surface and the atmosphere (Tian et al., 2004). However, feedback effects from the land surface to the atmosphere are not considered in this study. Vegetation development and land use/cover heterogeneity have a significant influence on climate model simulations such as predictions of surface temperature and precipitation. Thus, for the application in climate models, both the spatial and temporal distributions of vegetation are required with a high level of detail (Lu and Shuttleworth, 2002).
Acknowledgements. The research described in this paper was carried out at the Department of Geography of the Ludwig Maximilians Universität in Munich, Germany as part of the GLOWA-Danube project, which was funded by BMBF from 2000 to 2010. The support is gratefully acknowledged.

Edited by: N. Verhoest

\section{References}

Allen, R., Pereira, L., Raes, D., and Smith, M.: Crop evapotranspiration, FAO Irrigation and Drainage Paper 56, FAO, Rome, 300 pp., 1998.

Arino, O., Leroy, M., Ranera, F., Gross, D., Bicheron, P., Crockman, C., Defourny, P., Cancutsem, C., Achard, F., Durieux, L., and Bourg, L. et al:: Globcover - a global land cover service with MERIS, in: GlobCover at the Envisat Symposium, Montreux, Switzerland, April 2007, 2007.

Bach, H.: Die Bestimmung hydrologischer und landwirtschaftlicher Oberflächenparameter aus hyperspektralen Fernerkundungsdaten, Münchener Geographische Abhandlungen, B21, edited by: Birkenhauer, J., Gierloff-Emden, H. G., Mauser, W., Rögner, K., Rust, U., Wieneke, F. and Wilhelm, F., Munich, Germany, 175 pp., 1995.

Baret, F. and Guyot, G.: Potentials and limits of vegetation indices for LAI and APAR assessment, Remote Sens. Environ., 35, 161173, 1991.

Bartholomé, E. and Belward A. S.: GLC2000: a new approach to global land cover mapping from Earth observation data, Int. J. Remote Sensing, 26(9), 1959-1977, 2005.

Bicheron, P., Defourny, P., Brockmann, C.,Schouten L., Vancutsem C., Huc M., Bontemps S., Leroy M., Achard F., Herold M., Ranera F., and Arino O.: GLOBCOVER - Products Description and Validation Report, POSTEL and Medias-France, Toulouse, France, 47 pp., 2008.

Blunoua, L., Collatz, J. G., Los, S. O., Sellers, P. J., Dazlich, D. A., Tucker, C. J., and Randall, D. A.: Sensitivity of Climate to Changes in NDVI, J. Clim., 13, 2277-2292, 2000.

Bossard, M., Feranec, J., and Otahel, J.: CORINE Land Cover Technical Guide, EEA, Copenhagen, Technical report No 40, 105 pp., 2000.

Bsaibes, A., Courault, D., Baret, F., Weiss, M., Olioso, A., Jacov, F., Hagolle, O., Marloie, O., Bertrand, N., Desfond, V., and Kzemipour, F.: Albedo and LAI estimates from FORMOSAT-2 data for crop monitoring, Remote Sens. Environ., 113, 716-729, 2009. 
Cihlar, J.: Land cover mapping of large areas from satellites: status and research priorities, Int. J. Remote Sensing, 21, 1093-1114, 2000.

Defourny, P., Vancutsem, C., Bicheron, P., Brockmann, C., Nino, F., Schouten, L., and Leroy, M.: GLOBCOVER - A $300 \mathrm{~m}$ global land cover product for 2005 using ENVISAT MERIS time series, in: Proceedings of ISPRS Commission VII Mid-Term Symposium, Enschede, Netherlands, May 2006, 2006.

Defries, R. S. and Belward, A. S.: Global and regional land cover characterization from satellite data: an introduction to the Special Issue, Int. J. Remote Sensing, 21(6), 1083-1092, 2000.

Di Gregorio, A. and Jansen, L. J. M.: Land Cover Classification System (LCCS): Classification concepts and user manual, FAO, Rome, available at: http://www.fao.org/docrep/003/ x0596e/x0596e00.htm, access: 31 Mai 2010, 2000.

EEA (Ed.): The thematic accuracy of Corine land cover 2000, EEA, Copenhagen, Technical report No 7/2006, 90 pp., 2006.

Ge, J., Qi, J., Lofgren, B.M., Moore, N., Torbick, N., and Olson, J. M.: Impacts of land use/cover classification accuracy on regional climate simulations, J. Geophys. Res., 112, D05107, doi:10.1029/2006JD007404, 2007.

Herold, M., Mayaux, P., Woodcock, C. E., Baccini, A., and Schmullios, C.: Some challenges in global land cover mapping: An assessment of agreement and accuracy in existing $1 \mathrm{~km}$ datasets, Remote Sens. Environ., 112, 2538-2556, 2008.

Heymann, Y., Steenmans, Ch., Croissille G., and Bossard, M.: CORINE land cover, Technical guide, Office for Official Publications of the European Communities, Luxembourg, 137 pp., 1994.

Lambin, E. F. and Geist, H. (Eds.): Land-Use and Land-Cover Change, Local Processes and Global Impacts, The IGBP Series, Springer, Berlin, 222 pp., 2006.

Lobell, B. D. and Asner, G. P.: Cropland distributions from temporal unmixing of MODIS data, Remote Sensing of Environment, 93, 412-422, 2004.

Lokupitiya, E., Denning, S., Paustian, K., Baker, I., Schaefer, K., Verma, S., Meyers, T., Bernacchi, C. J., Suyker, A., and Fischer, M.: Incorporation of crop phenology in Simple Biosphere Model (SiBcrop) to improve land-atmosphere carbon exchanges from croplands, Biogeosciences, 6, 969-986, doi:10.5194/bg-6-9692009, 2009.

Lu, L. and Shuttleworth, W. J.: Incorporating NDVI-Derived LAI into the Climate Version of RAMS and Its Impact on Regional Climate, American Meteorological Society, 3, 347-362, 2002.

Ludwig, R., Probeck, M., and Mauser, W.: Mesoscale water balance modelling in the Upper Danube watershed using sub-scale land cover information derived from NOAA-AVHRR imagery and GIS-techniques, Physics and Chemistry on the Earth, 28, 1351-1364, 2003.
Masson, V., Champeaux, J-L., Chauvin, F. Meriguet, Ch., and Lacaze, R.: A Global Database of Land Surface Parameters at 1-km Resolution in Meteorological and Climate Models, J. Clim., 16, 1261-1282, 2002.

Mauser, W. and Bach, H.: PROMET - Large scale distributed hydrological modelling to study the impact of climate change on the water flows of mountain watersheds, J. Hydrol., 376, 362-377, 2009.

Mauser, W. and Schädlich, S.: Modelling the spatial distribution of evapotranspiration on different scales using remote sensing data, J. Hydrol., 212, 250-267, 1998.

Monfreda, C., Ramankutty, N., and Foley, J. A.: Farming the planet: 2. Geographic distribution of crop areas, yields, physiological types, and net primary production in the year 2000, Global Biochem. Cy., 22, GB1022, doi:10.1029/2007GB002947, 2008.

Monteith, J. L. and Unsworth, M. H.: Principles of environmental physics, 3rd Edition, edited by: Jeanne Lawson, Elsevier, London, 440 pp., 1990.

Neumann, K., Herold, M., Hartley, A., and Schmullius, C.: Comparative assessment of CORINE2000 and GLC2000: Spatial analysis of land cover data for Europe, Int. J. Appl. Earth. Obs., 9, 425-437, 2007.

Probeck, M., Ludwig, R., and Mauser, W.: Fusion of NOAAAVHRR imagery and geographical information system techniques to derive subscale land cover information for the upper Danube watershed, Hydrol. Process., 19, 2407-2418, 2005.

Richter, K. and Timmermans, W. J.: Physically based retrieval of crop characteristics for improved water use estimates, Hydrol. Earth Syst. Sci., 13, 663-674, 2009, http://www.hydrol-earth-syst-sci.net/13/663/2009/.

Swiss Federal Statistical Office (Ed.): Waldmischungsgrad der Schweiz, Bundesamt für Statistik, Sektion Geoinformation, Neuchâtel, 12 pp., 2004.

Tian, Y., Dickinson, R. E., Zhou, L., and Shaikh, M.: Impact of new land boundary conditions from Moderate Resolution Imaging Spectroradiometer (MODIS) data on the climatology of land surface variables, J. Geophys. Res., 109, D20115, doi:10.1029/2003JD004499, 2004.

Torbick, N., Lusch, D., Qi, J. Moore, N., Olson, J., and Ge, J.: Developing land use/land cover parameterization for climate-land modeling in East Africa, Int. J. Remote Sensing, 27, 4227-4244, 2006.

Waser, L. T. and Schwarz, M.: Comparison of large-area land cover products with national forest inventories and CORINE land cover in the European Alps, Int. J. Appl. Earth. Obs., 8, 196-207, 2006.

Zabel, F., Mauser, W., Marke, T., Pfeiffer, A., Zängl, G., and Wastl, C.: Two-way coupling the hydrological model PROMET with the regional climate model MM5, in: Geophysical Research Abstracts, 12, EGU General Assembly, Vienna, Austria, 3-8 Mai 2010, EGU2010-3140, 2010. 